\title{
A Containerized Liner Routing in Eastern Asia 東アジア地域におけるコンテナ船の配船計画
}

\section{INTRODUCTION}

This paper is concerned with a containerized ocean liner routing in Eastern Asia.

Containerized liner service is not profitable except for few carriers in these days. Due to the absence of distinct price competition in liner trades, the shipping companies are interested in how they can provide better services to their customers. However, the high standard of service is costly. As a result, most of liner carriers are intending to introduce the so-called global alliance, i.e., reorganizing partnership. This movement puts as many carriers as possible into a particular group, resulting in higher cost-effectiveness in liner services. That is, introducing larger vessels with fewer frequency of port calls, carriers involved share particular vessels so as to carry their own cargo. Thus the liner service likely has as few ports visited by deepsea vessels as possible and the other ports by feeder vessels to reduce the operating cost associated with the deepsea vessels. One of the issues is, therefore, how many ports should be called at and in what sequence they should be visited by particular deepsea vessels so as to guarantee shipper's satisfaction.

In a single objective problem by putting multiple objectives into a single objective function we obtain a unique optimal solution value. This notion of optimality must be dropped for multiobjective problems because a solution which minimizes one objective won't, in general, minimize any of the other objectives. Thus, since the mid 1970s there has been a growing interest in the use of

\section{Akio IMAI1 and Stratos PAPADIMITRIOU2 今井昭夫、Stratos PAPADIMITRIOU}

multiobjective techniques for the transportation network design. Among various approaches for the multiobjective analyses, of interest is identifying the noninferior solution set of the problem. By the noninferior set, we can explicitly consider the trade-offs between the multiobjectives.

Our problem assumes no competitions with other carriers in real situations of the shipping industry. The game theory can be useful to explicitly model the competitions. However, it is likely that all the competitors share equally the total amount of cargo[3]. Thus we implicitly consider the competition in this study using multiobjectives of carrier's and customer's costs. If one liner service in a solution doesn't satisfy the customers, they'll likely change liners to use. Thus, trade-off analyses with our problem can implicitly treat the competitive nature.

Due to the costly containerized liner service, most of the major container trades are supported by feeder services for the secondary transport between mother ports(or hub ports) and peripheral ports. This has made port choice for hubs one of the important issues. Thus, our study treats the liner routing and scheduling, taking into account secondary feeder transport.

\section{RELATED WORK}

The routing and scheduling of vehicles has been the focus of much research for the past few decades. Though there have been some attempts to analyze the ship routing and scheduling problem, only few of them pertain to

Keywards: Maritime Transportation, Port Planning

1. Regular member, Dr. Engg., Department of Transportation and Information Systems Engineering

Kobe University of Mercantile Marine, 1-1, 5-chome, Fukaeminamimachi, Higashinada-ku, Kobe 658 Japan Phone: +81-78-431-6261, Fax: +81-78-431-6365, E-mail: pdmb@bun.ti.kshosen.ac.jp

2. Non-member, Ph.D., Department of Maritime Studies, University of Piraeus

40 Karaoli and Dimitriou Street, 18532 Piraeus, Greece

Phone: +30-1-412-0751(ex.159), Fax:+30-1-412-5808, E-mail: stratos@cc.unip.gr 
container ships. Boffey et al.[2] implement an interactive computer system using an elaborated heuristic algorithm. Al-Kazily[1] models a containerized shipping for developing countries from economical point of view, but without routing considerations. Rana and Vickson[6] present a model on routing a time chartered ship to evaluate the profit potential in order to decide which ship to charter. Further, Rana and Vickson[7] extend the model for multiple ships.

Our problem can be considered to be the locationrouting problem for a hub choice. Imai[3] presents a port choice model for container traffic in Japan, however doesn't treat the routing issue. Further Imai[4] studies the locationrouting problem and shows its application to a container liner trade. This problem considers only one ship.

Imai et al. ${ }^{[5]}$ extends the problem for the multiple ship operations. Although they discuss in detail the solution procedure, they report only few case studies. In our study by using the algorithm developed by them we focus on how hub choices in Asia of deepsea vessel routes between Eastern Asia and the other areas affect the carrier's and customer's cost. We also discuss the influences of larger vessels to both carrier's and customer's costs and further see if all liner trades have the same influence of ship size.

\section{PROBLEM FORMULATION}

Despite of competitive circumstances, the service standard of each shipping company seems almost identical. For instance, they run their ships regularly(e.g., once a week for most liner routes). From this, assuming the service frequency of once a week, we consider one round trip of liner trades with no considerations of other factors such as the service frequency, etc. Thus we don't discuss a fleet size for a particular liner trade. In sum, given a fleet of liner vessels, we determine a set of hubs to be visited by vessels and routing of each vessel for one round trip.

For determining $F$ the fleet size of one round trip, the cargo amount of every port is given for one way of a cycle, assuming the amounts of inbound and outbound cargo are identical. We first determine $F$ in the following manner. Given $C$ the ship capacity and $V$ the total amount of cargo for a week, we calculate $|F|=[V / C / L]$ where $|F|$ is the cardinality of $F, L$ is the load factor, and [*] is the minimum integer no less than *. The identical ship capacity $C$ is assumed for the fleet, since in fact shipping companies likely provide a fleet with the unique ship size for the flexibility of ship operations.

The objective function of the carrier consists of cost incident to deepsea vessels and handling and storage costs at hubs, assuming every cargo waits for four days for loading on the ships or for shipper's picking up. The cost incident to a deepsea vessel is given by a function of the ship capacity and cruising time. The cruising time excludes the staying time in ports.

The objective function of the shippers includes feeder costs between their ports and hubs, and storage costs at origin and destination ports. The objective excludes the deepsea liner tariff. It is not, in general, open to public. Further, it is often observed that a different destination doesn't necessarily result in a different tariff especially for liner trades with a long distance between origin and destination ports. Consequently, we ignore the deepsea liner tariff for the objective. Note that introducing the tariff may affect obtaining noninferior solutions since hub choice varies the customer's cost.

As stated earlier, the cargo amount is given for one way. However, the associated cost is taken into account for both inbound and outbound trades.

We henceforth refer to deepsea and feeder vessels as ship and feeder, and routes of ship and feeder as primary and secondary routes, respectively. The network we use consists of arcs and nodes. We let a port denote a node with transport demands, a local port a port not on any primary routes, a $h u b$ a node on the primary route with or without feeder services connecting to local ports. By the definition a hub may not have its own cargo even though feeder cargo are transshiped there.

The problem may be formulated as a two-objective integer problem as follows:

Minimize $\quad\left(Z_{1}, Z_{2}\right)$

subject to

$$
\begin{aligned}
& \sum_{j \in M_{i}} u_{i j}^{v}-\sum_{j \in N_{i}} u_{j i}^{v}= \begin{cases}1 & (i=s, v \in F) \\
0 & (i \neq s, i \neq t, v \in F) \\
-1 & (i=t, v \in F)\end{cases} \\
& \sum_{i \in Q} \sum_{j \in Q} u_{i j}^{v} \leq|Q|-1
\end{aligned}
$$




$$
\begin{aligned}
& \sum_{j \in M_{i}} y_{i j}^{k v}-\sum_{j \in N_{i}} y_{j i}^{k v} \begin{cases}\leq 1 & (i=k, k \in K, v \in F) \\
=0 & \left(i \neq k, i \notin S^{v}, k \in K, v \in F\right) \\
\geq-1 & \left(i \in S^{v}, k \in K, v \in F\right)\end{cases} \\
& \sum_{j \in M_{k}} y_{k j}^{k v}=\sum_{j \in N p} y_{j p}^{k v} \quad\left(k \in K, p \in S^{v}, v \in F\right) \\
& \sum_{v \in F} \sum_{j \in M_{k}} y_{k j}^{k v} \geq 1 \quad(k \in K) \\
& U^{v}=\sum_{i \in P} \sum_{j \in P} h_{i j} u_{i j}^{v} \quad(v \in F) \\
& \sum g^{k v}=G^{k} \quad(k \in K) \\
& \sum_{k \in K} g^{k v} \leq C-\sum_{i \in S^{v}} G^{i} \quad(v \in F) \\
& Z_{1}=\sum_{v \in F}\left\{f^{M}\left(C, U^{v}\right)+\sum_{p \in S^{\nu}} 2\left(G^{p}+\sum_{i \in L_{p}} G^{i}\right)\left(H_{p}+T_{p}\right)\right\} \\
& Z_{2}=2\left\{\sum_{v \in F}\left[\sum_{k \in K} g^{k v} f^{S}\left(\sum_{i \in P} \sum_{j \in P} y_{i j}^{k v}\right)+\sum_{p \in S^{v}} \sum_{i \in L_{p}} G^{i} T_{i}\right]\right\} \\
& K=\left\{i \in P \mid \sum_{v \in F} \sum_{j \in N_{i}} u_{i j}^{v}=0\right\} \\
& L_{p}=\left\{k \in K \mid y_{i p}^{k v}=1, p \in S^{v}\right\} \quad(v \in F) \\
& S^{v}=\left\{k \in K \mid \sum_{k \in K} \sum_{v \in F} \sum_{j \in N_{i}} y_{j i}^{k v} \geq 1, \sum_{v \in F} \sum_{j \in M_{i}} u_{i j}^{v} \geq 1\right\} \\
& (v \in F) \\
& S^{v} \subseteq H B \quad(v \in F) \\
& u_{i j}^{v} \in(0,1) \quad(\forall \operatorname{arcs}(i, j), v \in F) \\
& y_{i j}^{k v} \in(0,1) \quad(\forall \operatorname{arcs}(i, j), k \in P, v \in F) \\
& g^{k v} \geq 0 \quad(k \in K, v \in F)
\end{aligned}
$$

where,

$C \quad$ : ship capacity

$F \quad:$ the set of ships

$K \quad:$ the set of local ports

$L_{p} \quad:$ the subset of $K$ such that ports are covered by feeders from hub $p$

$M_{i} \quad$ : the set of nodes being connected to node $i$ by an actual arc $(i, j)$

$N_{i} \quad$ : the set of nodes being connected to node $i$ by an actual arc $(j, i)$

$P \quad:$ the set of nodes

$Q \quad$ : the subset of $P$ in which every node has cargo

$S^{v} \quad$ : the set of hubs on the primary route of ship $v$

$H B$ : the set of hub candidates

$U^{v} \quad$ : cruising time of the primary route of ship $v$

$h_{i j} \quad:$ transport time from nodes $i$ to $j$
$f^{M}()$ : cost function of a ship

$f^{S}()$ : cost function of a feeder

$H_{p} \quad$ : handling cost per container at hub $p$

$T_{i} \quad$ : storage cost per container at port $i$

$G^{i} \quad$ : the amount of containers(in TEU) of port $i$

$s \quad:$ the origin of primary routes

$t \quad:$ the destination of primary routes

$u_{i j}^{v} \quad:=1$ if a primary route connects by ship $v$ nodes $i$ to $j,=0$ otherwise

$y_{i j}^{k v} \quad:=1$ if a secondary route to local port $k$ by ship $v$ connects nodes $i$ to $j,=0$ otherwise

$g^{k v} \quad$ : the amount of containers of local port $k$ sent from /to a hub on the primary route of ship $v$

The variables in the formulation are $u_{i j}^{v}, y_{i j}^{k v}$ and $g^{k v}$. If $\operatorname{arc}(i, j)$ is on the primary route of $\operatorname{ship} v$ connecting $i$ and $j$ then, $u_{i j}^{v}=1$, otherwise $u_{i j}^{v}=0$. Local port $k$ must be assigned to some nodes(i.e., hubs) by secondary routes of feeders. Then if $\operatorname{arc}(i, j)$ is on the secondary route between local port $k$ and the assigned hub visited by ship $v$, then, $y_{i j}^{k v}=1$, otherwise $y_{i j}^{k v}=0$.

Constraints (2) are conservation equations of flow to guarantee the primary routes. Constraint set (3) prohibits tours from occurring, therefore, assuring a simple path(i.e., a route never visits a particular node more than once) from $s$ to $t$. Constraints (4) and (5) are conservation equations of flow to guarantee the secondary routes. Equation set (6) ensures that a local port $k$ is connected to any hubs. Equations (7) represent the cruising time of the primary routes. Constraints (8) guarantee that containers of local port must be sent to hubs on any primary routes. Further equations (9) assure that the feeder cargo amount must be no more than surplus of the ship capacity minus the total amount of cargo of ports on her primary route. Equation (10) represents the carrier's objective that is the sum of cost borne by each ship. The cost for each ship consists of the ship cost function proportional to the ship capacity and cruising time, and the total of the costs at hubs proportional to the amount of cargo handled. Equation (11) represents the shipper's objective that is the sum of the feeder cost and cargo storage cost at origin and destination ports. Equations (12) to (14) define the sets $K, L_{p}$, and $S^{v}$. Constraint set

(15) assures that hubs must be chosen from candidates. 


\section{SOLUTION PROCEDURE}

In this section we briefly describe a solution procedure for our problem. For the detail of the procedure, see Imai and Papadimitriou[5].

A formal statement of the procedure for the ship routing follows:

Step 1. Given the maximum cruising time, $V L$, from $s$ to $t$, identify all of the primary routes between them within $V L$. Make all possible sets of primary route alternatives, each set consisting of a primary route for every ship.

Step 2. Given $C$, obtain $|F|$.

Step 3. For each primary route identified in Step 1, obta in a solution by the following procedure:

Step 3.1. For every node on the primary routes, find the shortest secondary routes to the ports not on any primary routes.

Step 3.2. Calculate the feeder costs for every pair of a node on the primary route and a local port.

Step 3.3. Solve the transportation problem to assign the cargo of local ports to the ships.

Step 3.4. Obtain values of the two objective functions.

Step 4. Identify noninferior solutions with respect to the dual objectives.

\section{ANALYSES OF ROUTING STRATEGIES}

\subsection{Cost Function of Ship}

We here describe the cost functions of deepsea and feeder vessels.

a. Cost function of deepsea vessel

The ship cost consists of two factors: capital cost and operating cost. In general the capital cost includes costs regarding ship herself, while the operating cost contains costs of crew, fuel, and others regarding operation. In our study, however, for the sake of simplicity we divided the overall ship cost into cost of energy(including fuel and lubricating oil) and the others as fixed cost.

The energy cost consists of fuel and lubricating oil costs that are given by the following equations.

$C E=C F+C L=\left(C^{F} R^{F}+C^{L} R^{L}\right) D^{2 / 3}\left(S^{N}\right)^{3} T^{N} / A$ where $C F$ is the fuel $\operatorname{cost}(\$ 450 /$ ton $), R^{F}$ the fuel consumption rate( $140 \mathrm{~g} /$ horsepower/hour), $C L$ is the oil $\operatorname{cost}(\$ 2400 /$ ton $)$ and $R^{L}$ the oil consumption rate $(4 \mathrm{~g} /$ horse power/hour), $D$ displacement, $S^{N}$ cruising speed, $T^{N}$ cruising time(in hours), and $A$ the admiralty coefficient $(=425)$.

We classify the fixed cost into those dependent on and independent from ship size. The former cost includes capital cost with interest, cost of insurance, and tax. Assuming the capital cost is annualized at interest of $0.3 \%$ over a vessel life of 20 years, we give the cost per ship per day by

$C D=0.000047 C+0.0046 \quad\left(R^{2}=0.77\right)$

where $C$ is ship capacity. The latter cost contains crew cost, repair cost, business expenses including management tasks, and others. The cost(in US\$) per ship per day is the following value.

$C I=\mathrm{US} \$ 42,263$

The deepsea vessel cost is given by the following equation.

$f^{M}()=C D+C I+C E$

b. Cost function of feeder vessel

We define the feeder cost as the sum of all the cost borne from local ports to hubs, i.e., feeder tariff and inventory carrying cost.

In general the feeder tariff is not open to public. We obtained that from some freight-forwarders providing feeder services in Asia. Assuming the tariff, FT(US\$ for a 20 -foot container), is proportional to the cruising time, we obtain the following estimation model by a regression analysis.

$F T=24.3 T^{N}+750.4 \quad\left(R^{2}=0.12\right)$

The inventory carrying cost is given by multiplying the interest per day of the cargo value in a 20 -foot container by the cruising time. Assuming that the average cargo value per 20-foot container is US\$75,000 and the interest per year is $12 \%\left(3.3 \times 10^{-4}\right.$ per day), we have the inventory carrying $\cos t=24.7 T^{N}$.

Therefore the feeder cost is given as below:

$f^{S}()=49.0 T^{N}+750.4$

\subsection{Routing Strategies}

We conducted numerical experiments for two container trades: one for North America and the other for Europe. 
Mother ships depart from and return to Oakland in the former and Rotterdam in the latter, visiting some ports in Asian region as hubs in both of the trades. The set of hub candidates consists of Tokyo, Kobe, Busan, Kaohsiung, HongKong, and Singapore.

The handling and storage costs in major Asian ports are detailed in a comprehensive port survey conducted by Secretariat of International Federation of Port Cargo Distribution[8]. In that survey all charges are given per TEU but in local currency. For the sake of simplicity, we standardized, with the assumption of four day storage of cargo at ports, the charges of those Asian ports in US\$ for TEU as represented in Table 1. The charges for ports not included in the survey are estimated by the data of ports geographically close to those.

Assuming the total amount for each of inbound and outbound trades is 9000 TEU, we obtain a container distribution of each Asian country to the two continents by using the share of each country's cargo volume to the total of outside Asia. As a result, each country has the same container volume to both continents as shown in Table 1 .

We conducted the experiments with $V L=32$ days in North American trade and $V L=60$ days in European trade, respectively, which are the minimum values to find primary routes visiting all the hub candidates.

We first identified noninferior solution sets, given the ship sizes of 4500, 6500, and 13000 TEUs for each trade. We assume the load factor of 0.7 for each ship sizes. 13000TEU ships have not yet appeared in container liner trades; however we consider this size in our study to see how such large ships influence the liner operation.

The results for North American trade are shown in Tables 2. The average size of ship built recently is considered to be approximately 4500 TEU. Thus, a noninferior solution set using 4500-TEU ships is supposed to be the optimal solution for the present shipping industry. Most of major liners for North American trade connect Japan and Korea; and Taiwan, Hong Kong, and Singapore. Thus, in the solution set, solution \# 13 in which all the hub candidates are selected is close to the currently standard set of routes between the west coast of North America and Asia. Figure 1-a graphically shows the set of primary routes and local port-hub connections in solution 13. It is not realistic that Bangkok is connected to Kobe, because in the algorithm the cargo of hubs are primarily assigned to the ships visiting the hubs and local ports are not necessarily assigned to their closest hubs due to insufficient ship capacity. From the solution, we can identify that the shipping company's cost is $\$ 30.5$ million and the customer's cost per TEU is approximately $\$ 310$.

With the above carrier's and customer's costs, we next identify the sets of routes by using larger ships. In the corresponding solution sets, solutions with cost criterion of $Z_{1}<\$ 30.5$ million and $Z_{2}(\$ / T E U)<\$ 310$ is considered to be desirable for the shipping company, since both carrier's and customer's satisfactions to the cost are met with those solutions. When using 6500-TEU ships, solution \# 10 only falls into the cost criterion. The service network of solution 10 is represented by Figure 1-b, where all the hub candidates are selected. For 13000-TEU ship, no solutions satisfy this criterion. This means that given the current port charges, the scale of economy using such a large ship is not useful. However, its benefit is obvious for a particular value of $Z_{2}$, resulting in the reduced $Z_{1}$.

Solutions for European trade are revealed in Table 3. Noninferior solution \# 13 for 4500-TEU ship can be considered to be realistic. Figure 2-a graphically shows the set of primary routes and local port-hub connections in solution 13. It is of interest that Kobe is not selected for a hub and connected to Busan. In fact some carrier adopts such a routing strategy. From the solution, we can identify that the carrier's cost is roughly $\$ 53.0$ million and the customer's cost per TEU is approximately $\$ 400 . Z_{2}$ of the solution is higher than that of the realistic solution for 4500-TEU ships in North American trade.

When using 6500-TEU ships, solutions \# 10 and 11 fall into the cost criterion where all the hub candidates are

TABLE 1. Port Charges(US\$/TEU) and Transport Demands(TEU/week)

\begin{tabular}{llllllllll}
\hline Port TO NA KO BU KE KA HK & SH MA JA & SI & PE & BA \\
\hline
\end{tabular} $\begin{array}{llllllllllllll}\text { H.C. } 750 & 750 & 750 & 100 & 110 & 110 & 200 & 200 & 550 & 70 & 140 & 110 & 50\end{array}$ $\begin{array}{llllllllllllll}\text { S.C. } & 10 & 10 & 10 & 10 & 10 & 10 & 0 & 0 & 310 & 10 & 0 & 0 & 0\end{array}$

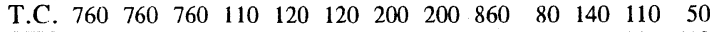

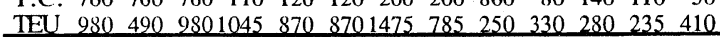

BA:Bangkok, BU:Busan, HK:Hong Kong, JA:Jakarta, KA:Kaohsiung, KE:Keelung, KO:Kobe, MA:Manila, NA:Nagoya, OA: Oakland, PE:Penang, SH:Shanghai, SI:Singapore, TO:Tokyo H.C.:Handling Charge, S.C.:Storage Charge, T.C..Total Charge 
TABLE 2. Noninferior Solution Set for North American Trade

\begin{tabular}{|c|c|c|c|c|c|c|}
\hline $\begin{array}{c}C \\
(\mathrm{TEU})\end{array}$ & $\begin{array}{c}V L \\
\text { (days) } \\
\end{array}$ & Sol.\# & $\begin{array}{c}Z_{1} \\
\left(X \$ 10^{4}\right) \\
\end{array}$ & $\begin{array}{l}\text { Total } \\
\left(X \$ 10^{4}\right)\end{array}$ & $\underset{(\$)}{\mathrm{Cost} / \mathrm{TEU}}$ & Hubs \\
\hline 4500 & 32 & $\begin{array}{r}1 \\
2 \\
3 \\
4 \\
5 \\
6 \\
7 \\
8 \\
9 \\
10 \\
11 \\
12 \\
13 \\
14 \\
15\end{array}$ & $\begin{array}{l}2412 \\
2530 \\
2584 \\
2603 \\
2618 \\
2692 \\
2700 \\
2806 \\
2865 \\
2873 \\
2947 \\
2950 \\
3050 \\
3125 \\
3141\end{array}$ & $\begin{array}{r}1463 \\
1289 \\
1194 \\
1039 \\
1026 \\
940 \\
801 \\
792 \\
774 \\
635 \\
631 \\
627 \\
566 \\
563 \\
554\end{array}$ & $\begin{array}{l}812.8 \\
716.2 \\
663.1 \\
577.3 \\
570.1 \\
522.2 \\
445.0 \\
439.8 \\
430.2 \\
353.0 \\
350.8 \\
348.4 \\
314.3 \\
313.0 \\
308.0\end{array}$ & $\begin{array}{l}\text { [BU][BU][BU] } \\
\text { [BU][BU][KA] } \\
\text { [BU,HK][BU][BU] } \\
\text { [BU,KA,HK][BU][BU] } \\
\text { [KA,HK][BU][BU] } \\
\text { [TO][BU][HK] } \\
\text { [TO][BU][KA,HK] } \\
\text { [TO][BU,KA][HK] } \\
\text { [KO,BU][TO][HK] } \\
\text { [KO,BU][TO][KA,HK] } \\
\text { [KO,HK][TO][BU,KA] } \\
\text { [KO,BU,KA][TO][HK] } \\
\text { [KO,BU][TO][KA,SI,HK] } \\
\text { [KO,SI,HK][TO][BU,KA] } \\
\text { [KO,BU,KA,TO][TO,SI,HK,BU][TO] }\end{array}$ \\
\hline 6500 & 32 & $\begin{array}{r}1 \\
2 \\
3 \\
4 \\
5 \\
6 \\
7 \\
8 \\
9 \\
10\end{array}$ & $\begin{array}{l}2185 \\
2333 \\
2426 \\
2440 \\
2617 \\
2631 \\
2767 \\
2774 \\
2782 \\
3020\end{array}$ & $\begin{array}{r}1463 \\
1234 \\
1107 \\
968 \\
931 \\
792 \\
766 \\
654 \\
627 \\
554\end{array}$ & $\begin{array}{l}812.8 \\
685.4 \\
615.1 \\
537.8 \\
517.0 \\
439.8 \\
425.7 \\
363.6 \\
348.4 \\
308.0\end{array}$ & $\begin{array}{l}\text { [BU][BU] } \\
\text { [BU][KA] } \\
\text { [BU][HK] } \\
\text { [BU][KA,HK] } \\
\text { [TO,HK][BU] } \\
\text { [TO,KA,HK][BU] } \\
\text { [KO,BU][TO,HK] } \\
\text { [KO,HK,KA,TO][BU] } \\
\text { [KO,BU][TO,KA,HK] } \\
\text { [KO,BU][TO,KA,SI,HK] }\end{array}$ \\
\hline 13000 & 32 & $\begin{array}{r}1 \\
2 \\
3 \\
4 \\
5 \\
6 \\
7 \\
8 \\
9 \\
10\end{array}$ & $\begin{array}{l}1994 \\
2261 \\
2294 \\
2424 \\
2457 \\
2616 \\
2648 \\
2784 \\
2817 \\
3259\end{array}$ & $\begin{array}{r}1463 \\
1452 \\
1234 \\
1107 \\
968 \\
931 \\
792 \\
766 \\
627 \\
554\end{array}$ & $\begin{array}{l}812.8 \\
806.8 \\
685.4 \\
615.1 \\
537.8 \\
517.0 \\
439.8 \\
425.7 \\
348.4 \\
308.0\end{array}$ & $\begin{array}{l}\text { [BU] } \\
\text { [KA] } \\
\text { [BU,KA] } \\
\text { [BU,HK] } \\
\text { [BU,KA,HK] } \\
\text { [TO,HK,BU] } \\
\text { [TO,KA,HK,BU] } \\
\text { [KO,BU,HK,TO] } \\
{[\mathrm{KO}, \mathrm{BU}, \mathrm{HK}, \mathrm{KA}, \mathrm{TO}]} \\
\text { [KO,BU,HK,SI,KA,TO] }\end{array}$ \\
\hline
\end{tabular}

TABLE 3. Noninferior Solution Set for European Trade

\begin{tabular}{|c|c|c|c|c|c|c|}
\hline \multirow{2}{*}{$\begin{array}{c}C \\
(\mathrm{TEU})\end{array}$} & \multirow{2}{*}{$\begin{array}{c}V L \\
\text { (days) }\end{array}$} & \multirow[t]{2}{*}{ Sol.\# } & \multirow{2}{*}{$\begin{array}{c}Z_{1} \\
\left(X \$ 10^{4}\right)\end{array}$} & \multicolumn{2}{|c|}{$Z_{2}$} & \multirow[t]{2}{*}{ Hubs } \\
\hline & & & & $\begin{array}{l}\text { Total } \\
\left(\times \$ 10^{+}\right)\end{array}$ & $\underset{(\$)}{\operatorname{Cost} / T E U}$ & \\
\hline 4500 & 60 & $\begin{array}{r}1 \\
2 \\
3 \\
4 \\
5 \\
6 \\
7 \\
8 \\
9 \\
10 \\
11 \\
12 \\
13 \\
14 \\
15 \\
16 \\
17\end{array}$ & $\begin{array}{l}4367 \\
4616 \\
4627 \\
4670 \\
4764 \\
4959 \\
5011 \\
5139 \\
5154 \\
5204 \\
5256 \\
5285 \\
5311 \\
5384 \\
5386 \\
5427 \\
5473\end{array}$ & $\begin{array}{r}1681 \\
1425 \\
1332 \\
1201 \\
997 \\
829 \\
823 \\
788 \\
785 \\
741 \\
736 \\
733 \\
719 \\
700 \\
569 \\
561 \\
554\end{array}$ & $\begin{array}{l}934.0 \\
791.4 \\
739.8 \\
667.2 \\
554.1 \\
460.4 \\
457.1 \\
437.6 \\
436.0 \\
411.8 \\
408.7 \\
407.3 \\
399.3 \\
389.0 \\
316.0 \\
311.8 \\
308.0\end{array}$ & $\begin{array}{l}\text { [SI][SI][SI] } \\
\text { [KA,SI][SI][SI] } \\
\text { [HK,SI][SI][SI] } \\
\text { [KA,HK,SI][SI][SI] } \\
\text { [KA,BU,HK,SI][SI][SI] } \\
\text { [HK,KA,BU,KO,SI][SI][SI] } \\
\text { [KA,TO,BU,HK,SI][SI][SI] } \\
\text { [TO,KO,BU,HK,SI][SI][SI] } \\
\text { [KA,TO,KO,BU,HK,SI][SI][SI] } \\
\text { [HK,KA,BU,KO,SI][HK,SI][SI] } \\
\text { [KA,TO,BU,HK,SI][HK][SI] } \\
\text { [TO,BU,HK,SI][KA,SI][SI] } \\
\text { [KA,BU,TO,SI][KA,HK,SI][SI] } \\
\text { [TO,KO,BU,HK,SI][HK,SI][SI] } \\
\text { [TO,KO,BU,HK,SI][KA,SI][SI] } \\
\text { [TO,KO,BU,HK,SI][KA,HK,SI][SI] } \\
\text { [TO,BU,KO,SI][KA,HK,SI][SI] }\end{array}$ \\
\hline 6500 & 60 & $\begin{array}{r}1 \\
2 \\
3 \\
4 \\
5 \\
6 \\
7 \\
8 \\
9 \\
10 \\
11\end{array}$ & $\begin{array}{l}3934 \\
4269 \\
4288 \\
4349 \\
4468 \\
4750 \\
4783 \\
4797 \\
4956 \\
4971 \\
5229\end{array}$ & $\begin{array}{r}1681 \\
1391 \\
1271 \\
1133 \\
930 \\
895 \\
891 \\
753 \\
727 \\
589 \\
554\end{array}$ & $\begin{array}{l}934.0 \\
772.6 \\
706.3 \\
629.6 \\
516.4 \\
497.4 \\
495.1 \\
418.4 \\
403.7 \\
327.0 \\
308.0\end{array}$ & $\begin{array}{l}\text { [SI][SI] } \\
{[\mathrm{KA}, \mathrm{SI}][\mathrm{SI}]} \\
{[\mathrm{HK}, \mathrm{SI}][\mathrm{SI}]} \\
{[\mathrm{KA}, \mathrm{HK}, \mathrm{SI}][\mathrm{SI}]} \\
{[\mathrm{KA}, \mathrm{BU}, \mathrm{HK}, \mathrm{SI}][\mathrm{SI}]} \\
{[\mathrm{KA}, \mathrm{BU}, \mathrm{HK}, \mathrm{SI}][\mathrm{HK}, \mathrm{SI}]} \\
{[\mathrm{TO}, \mathrm{BU}, \mathrm{HK}, \mathrm{SI}][\mathrm{SI}]} \\
{[\mathrm{KA}, \mathrm{TO}, \mathrm{BU}, \mathrm{HK}, \mathrm{SI}][\mathrm{SI}]} \\
{[\mathrm{TO}, \mathrm{KO}, \mathrm{BU}, \mathrm{HK}, \mathrm{SI}][\mathrm{SI}]} \\
{[\mathrm{KA}, \mathrm{TO}, \mathrm{KO}, \mathrm{BU}, \mathrm{HK}, \mathrm{SI}][\mathrm{SI}]} \\
{[\mathrm{KA}, \mathrm{BU}, \mathrm{KO}, \mathrm{TO}, \mathrm{SI}][\mathrm{HK}, \mathrm{SI}]}\end{array}$ \\
\hline 13000 & 60 & $\begin{array}{l}1 \\
2 \\
3 \\
4 \\
5 \\
6 \\
7 \\
8\end{array}$ & $\begin{array}{l}3571 \\
4162 \\
4277 \\
4517 \\
4924 \\
4957 \\
5134 \\
5167\end{array}$ & $\begin{array}{r}1681 \\
1239 \\
1100 \\
895 \\
858 \\
719 \\
693 \\
554\end{array}$ & $\begin{array}{l}934.0 \\
688.6 \\
611.3 \\
497.4 \\
476.6 \\
399.3 \\
385.2 \\
308.0\end{array}$ & $\begin{array}{l}\text { [SI] } \\
\text { [HK,SI] } \\
\text { [KA,HK,SI] } \\
\text { [KA,BU,HK,SI] } \\
\text { [TO,BU,HK,SI] } \\
\text { [KA,TO,BU,HK,SI] } \\
\text { [TO,KO,BU,HK,SI] } \\
\text { [KA,TO,KO,BU,HK,SI] }\end{array}$ \\
\hline
\end{tabular}




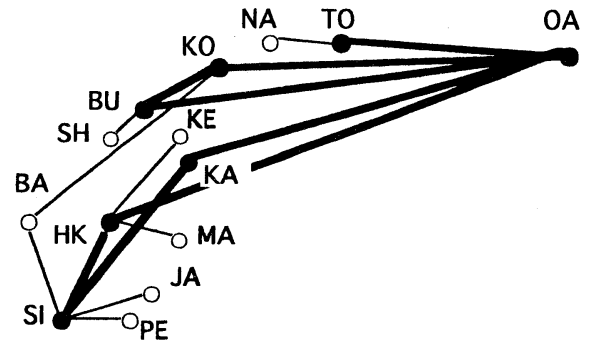

a. Solution \#13 Using 4500-TEU Ships

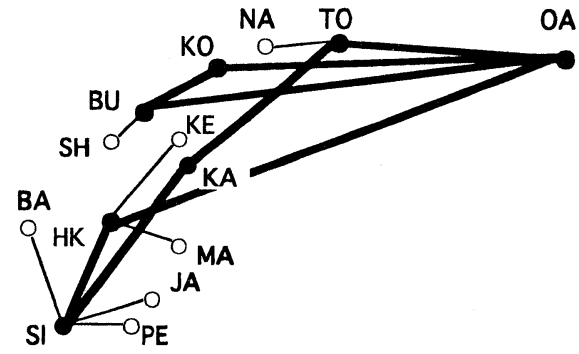

b. Solution \#10 Using 6500-TEU Ships

FIGURE 1. Ship Routing for North American Trade

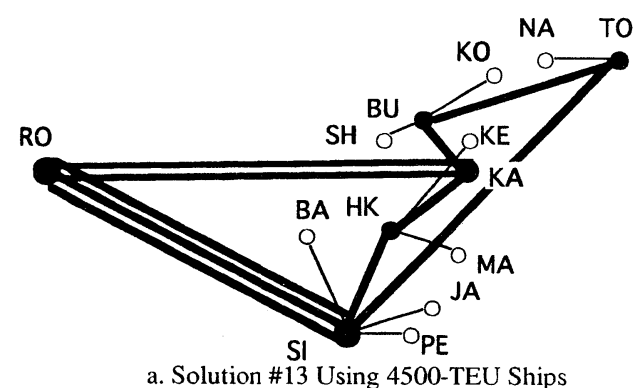

a. Solution \#13 Using 4500-TEU Ships

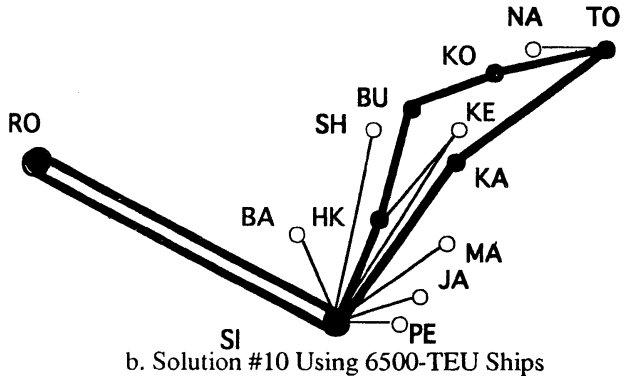

b. Solution \#10 Using 6500-TEU Ships

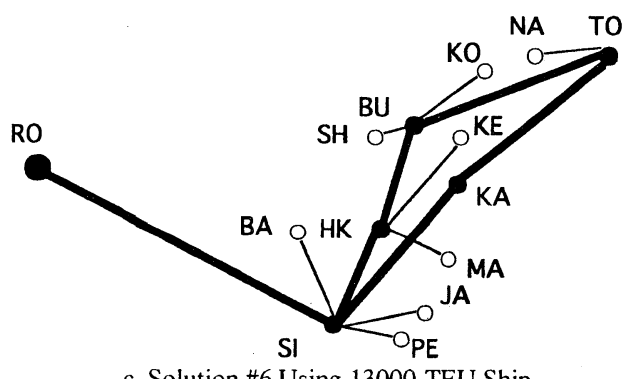

c. Solution \#6 Using 13000-TEU Ship

FIGURE 2. Ship Routing for European Trade

TABLE 4. Noninferior Solution Set for North American Trade ( $C=4500-13000 T E U, V L=32$ days $)$

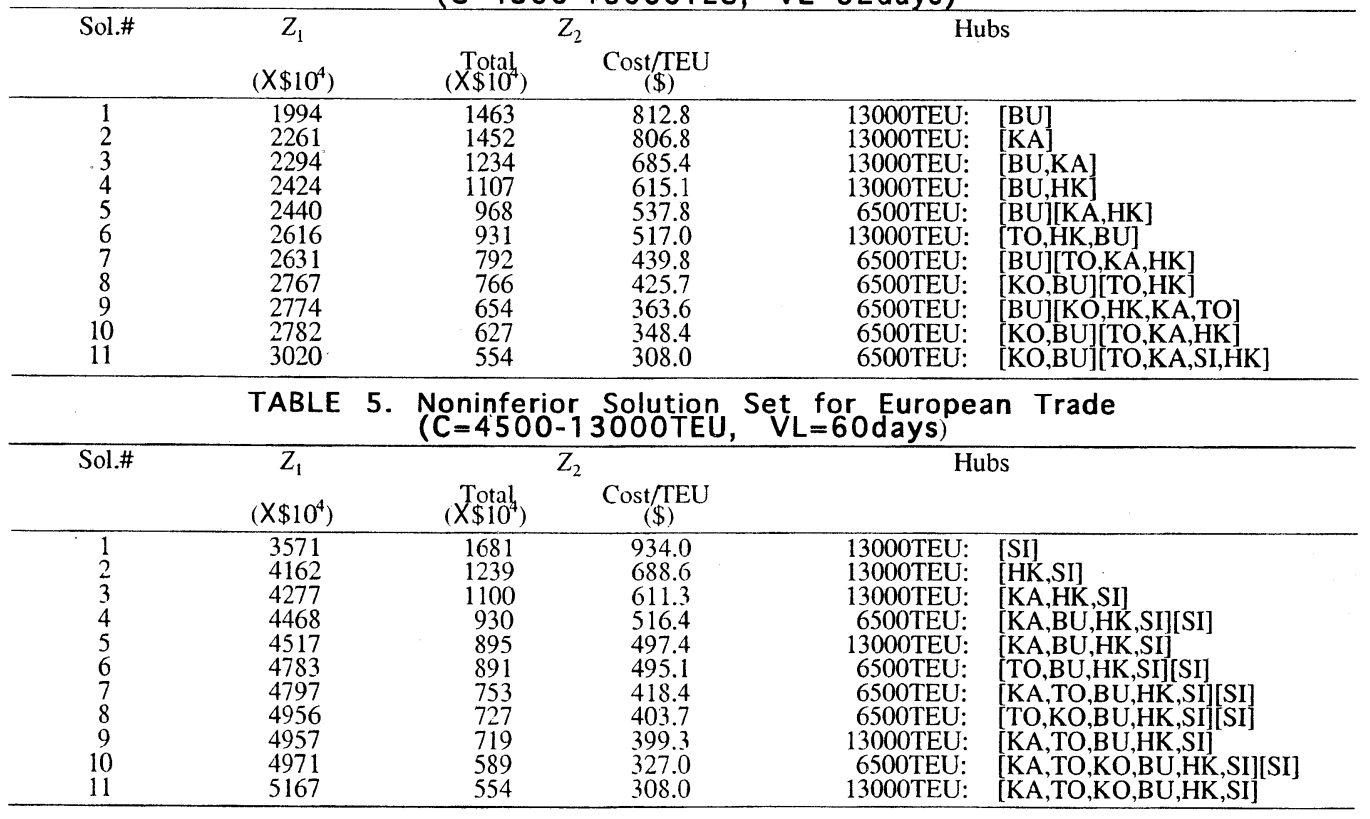


chosen. The service networks of solution 10 is illustrated in Figure 2-b. For 13000-TEU ship, solutions 6-8 satisfy this criterion. Note that while all the hub candidates are selected in solution 8, they are not all chosen in both solutions 6 and 7. Figure 2-c shows the service routes for solution 6 . Thus, the scale of economy using larger ships is acceptable for European trade. Further, for a particular value of $Z_{2}, Z_{1}$ is reduced with larger ship size like North American trade.

Next, given the noninferior sets, each for 4500, 6500, or 13000 TEUs, we identify the noninferior sets for both trades where any size of ship is considerable under the assumption that the unique ship size must be used in each solution. The solution sets for both trade are shown in Tables 4 and 5. In North American trade, no solutions using 4500-TEU ships are found and solution 11 only satisfies the cost criterion. For European trade, we cannot find any solutions with 4500-TEU ships either. We have more solutions satisfying the cost criterion than for North American trade. From Tables 4 and 5, the scale of economy is considerably effective for the cost reduction of carrier while maintaining the standard of shipper's cost.

Next, we consider what kind of strategies the ship operator takes to minimize its cost with ignoring the customer's cost. Solution 1 with each size of ship in Table 2 and that in Table 3 are met for this purpose in North American and European trades, respectively. Busan is selected for a hub in the former trade, whilst Singapore in the latter. Both ports are geographically the closest to the destination for the respective trades. Interestingly almost all solutions 2 for every ship size for both trades select Kaohsiung. This means that if a particular carrier or a group of carriers places a hub that services both trades at the same time, they likely choose Taiwan for that. Furthermore, if they take into account more customer's satisfactions, as seen in solutions 3 or 4, they may select Taiwan or HongKong.

It is of interest that no Japan's ports are chosen for those solutions in both trades due to their high port charges.

\section{CONCLUSIONS}

In this study we presented the container ship routing problem in Eastern Asia with the minimization of the carrier's cost and the minimization of the cost borne by shippers associated with the secondary feeder routes. We here enabled to explicitly treat the shipper's satisfaction and see how the ship size contributes in reducing the carrier's cost.

\section{REFERENCES}

1. J. Al-Kazily, "Modeling Containcrized Shipping for Developing Countries," Transportation Research 16A, 271 283 (1982).

2. T.B. Boffey, E.D. Edmond, A.I. Hinxman, and C.J. Pursclove, "Two Approaches to Schcdulng Container Ships With an Applicationtothe North Atlantic Route,"Journal of Operationl Research Society 30,413-425(1979).

3. A. Imai, "An Optimal Facility Planning for Containerized Shippingunde rMu lt i-carrie rCompetition, "Infrast ruc ture Planning Review 6, 37-44(1988).

4. A. Imai, "A Two-objective Terminal Location Problem with a Routing Planning," Infrastructure Planning Review 10, 239246(1992).

5. A. Imai and S. Papadimitriou,"A Containerized Liner Routing with Multiobjective Approach," submitting to Transportation Science.

6. K. Rana and R.G. Vickson, "A Model and Solution Algorithm for Optimal Routing of a Time-Chartered Containership," Transportation Science 22, 83-95 (1988).

7. K. Rana and R.G. Vickson, "Routing Container Ships Using Lagrangean Relaxation and Decomposition," Transportation Science 25, 201-214 (1991).

8. Secretariat of International Federation of Port Cargo Distribution, Survey on the Cargo Distribution in East and Southeast Asian Ports, The International Port Cargo Distribution Association of Japan (1994).

東アジア地域におけるコンテナ船の配船計画

今井昭夫、Stratos PAPADIMITRIOU

近年、グローバルアライアンスと呼ばれる協調配船グループの再編成がコンテナ定期船の分野で行われている。 これにより大型船の投入や東アジア地域でのハブ港の再配置といった航路形態の大きな恋化が予想される。本研 究では船社と荷主の 2 目的を有する数理計画問題を用いて、東アジア地域でのコンテナ船航路の戦略について考 祭を加える。

A Containerized Liner Routing in Eastern Asia

Akio IMAI and Stratos PAPADIMITRIOU

New partnerships has been made in containerized liner services. This likely results in drastic changes in ship size and hub location in Eastern Asia. In this study we address strategies of the containerized liner services by using a mathematical programming with two objectives of shipping company and customer. 